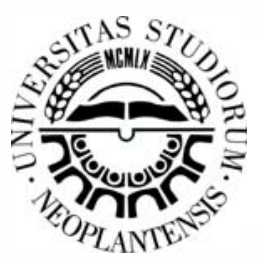

\title{
Weld Cladding of s355 Steel with Rectangular Electrode Covered Rutile 2000 s Coating
}

\author{
Edvard Bjelajac, * Tomaž Vuherer, Gorazd Lojen
}

University of Maribor, Faculty of Mechanical Engineering, Smetanova ulica 17, 2000 Maribor, Slovenia

\begin{abstract}
Weld cladding or weld overlay is a frequently used method for repair welding of damaged surfaces and for production of different surface coatings. The conventional coated electrodes have a circular cross-section. In order to increase the productivity and to decrease dilution and the depth of the heat affected zone (HAZ), the geometry of the electrode core was modified. Experimental weld cladding was carried out with rutile coated electrodes of rectangular cross-sections of $12.56 \times 1 \mathrm{~mm}^{2}$, and for reference, also with a conventional $\phi 4 \mathrm{~mm}$ electrode Rutilen $2000 \mathrm{~S}$. The coating of rectangular electrodes was identical and the core material almost identical to the materials of the standard electrode. The base material was the structural steel S355JR.

The goal of investigation was to determine the welding parameters for the rectangular electrodes and to compare geometries and mechanical properties of the welds. Hardness and the dimensions of weld metal and HAZ were measured. Results with the $6.28 \times 2 \mathrm{~mm}^{2}$ and $6.28 \times 2 \mathrm{~mm}$ electrode were similar to the results with the standard electrode. However, with the $12.56 \times 1 \mathrm{~mm}^{2}$ rectangular electrode, significantly lower currents were sufficient to obtain a good quality of the deposition layer. Due to possibility to weld with currents as low as 80-100 A, shallower and smaller HAZs and less dilution can be achieved with the rectangular $12.56 \times 1 \mathrm{~mm}^{2}$ electrode than with standard cylindrical $\phi 4 \mathrm{~mm}$ electrode.
\end{abstract}

Key words: Weld cladding; SMAW; rectangular coated electrode; weld geometry; dilution.

\section{$1 \quad$ INTRODUCTION}

Wear and corrosion resistance of machinery is one of the most common problems in industry applications. To increase product service life, there are many surface coating techniques available, such as plasma spraying, thermal spraying, hardfacing, laser cladding, chemical and physical vapor deposition processes [1-6]. In industrial applications, weld cladding is a widely used process for creating adequate mechanical or chemical properties of surface layers. It is applicable, when thick surface layers are required.

Cladding with fusion welding is a process for surface modification by adding new material onto the surface in order to obtain adequate surface properties, like corrosion resistance, wear resistance, hardness or conductivity.

The conventional coated electrodes for manual weld cladding exhibit a circular cross-section [7]. Modification of surface properties with SMAW process with standard round shaped electrodes is mostly used in areas and applications where higher productivity fusion welding with SAW or GMAW process is not possible to use.

While a lot of research in SMAW cladding process was dedicated to development of coating optimization for specific applications [8,9], no reports were found on influence of the core cross-section shape. Cross-section of electrode plays an important role in temperature distribution to base material during cladding and consequently on the depth of the fusion zone and HAZ. To achieve improvement of performance of coated electrodes for weld cladding, the standard round shape cross-section was changed to rectangular cross-section. We applied a moderate thickness of coating to achieve optimum drying process of the coating and optimum weldability. Because of changed geometry, also the welding parameters had to be changed [10-11].

* Corresponding author's.e-mail: edvard.bjelajac@gmail.com 


\section{EXPERIMENTAL PROCEDURE}

\subsection{Preparation of the rectangular coated electrodes}

As the main purpose was to test the influence of the corecross-section shape, an already existing coating was applied. The non-alloyed full rutile type coating of standard electrode Rutilen 2000 S was chosen, regularly produced by SIJ Elektrode Jesenice d.o.o. The metal core was laser-cut from cold rolled steel sheets, grade DC 01, EN 10 130. Oil was removed from metal core surface after cutting process. The chemical composition of core made from cold rolled sheets was very similar to core wire of the standard electrode Rutlen 2000 S, made by Elektrode Jesenice d.o.o., Table 1.

Table 1: Analysed chemical composition of standard round and rectangular electrode core

\begin{tabular}{lccccc}
\hline Element wt.\% & $\boldsymbol{C}$ & $\boldsymbol{S i}$ & $\boldsymbol{M n}$ & $\boldsymbol{P}$ & $\boldsymbol{S}$ \\
\hline $\begin{array}{l}\text { Rectangular } \\
\text { Rutilen 2000 S }\end{array}$ & 0.09 & 0.25 & 0.54 & 0.025 & 0.025 \\
\hline $\begin{array}{l}\text { Standard } \\
\text { Rutilen 2000 S }\end{array}$ & 0.07 & 0.03 & 0.51 & 0.015 & 0.01 \\
\hline
\end{tabular}

Dimensions of the rectangular and the standard round $\phi 4$ $\mathrm{mm}$ electrode are summarized in the Table 2 . The dimensions of the rectangular electrode core crosssection were selected according to following demands:

- The metallic core cross-section of the rectangular electrode should be equal to the core cross-section of the standard $\phi 4 \mathrm{~mm}$ round electrode.

- The cross-section should be wide and thin in order to achieve low energy inputs into the base material, where the minimum thickness was limited by still acceptable weldability.

Table 2: Coating factor of round and rectangular electrode Rutilen $2000 \mathrm{~S}$

\begin{tabular}{lcc}
\hline & $\begin{array}{c}\text { Rectangular } \\
\text { Rutilen } \\
\mathbf{2 0 0 0 ~ S}\end{array}$ & $\begin{array}{c}\text { Round standard } \\
\text { Rutilen } 2000 \mathrm{~S}\end{array}$ \\
\hline $\begin{array}{l}\text { Metallic core } \\
\text { crosssection } \text { Am }\end{array}$ & $12.56 \mathrm{~mm}^{2}$ & $12.56 \mathrm{~mm}^{2}$ \\
\hline $\begin{array}{l}\text { Coating } \\
\text { crosssection } \\
\text { Ac }\end{array}$ & $25.52 \mathrm{~mm}^{2}$ & $22.96 \mathrm{~mm}^{2}$ \\
\hline $\begin{array}{l}\text { Coating factor } \\
\text { Ac/Am }\end{array}$ & 2.03 & 1.83 \\
\hline Core & Series $\mathrm{H}:$ & $\begin{array}{c}\text { Series } \mathrm{M}: \\
\phi 4 \mathrm{~mm}\end{array}$ \\
\hline Core & $\begin{array}{c}\text { Series } \mathrm{K}: \\
6.28 \times 2.0 \mathrm{~mm}\end{array}$ & \\
\hline Total length & $206 \mathrm{~mm}$ & $450 \mathrm{~mm}$ \\
\hline Coated length & $198 \mathrm{~mm}$ & $425 \mathrm{~mm}$ \\
\hline
\end{tabular}

The total length of rectangular electrodes was $206 \mathrm{~mm}$, while the coated length was about $198 \mathrm{~mm}$. Two different rectangular cross-sections shapes were tested: $12.56 \times 1$ $\mathrm{mm} 2$ and $6.28 \times 2 \mathrm{~mm}^{2}$.
Due to combination of good mechanical properties and easy machining, aluminum alloy A5083 was chosen for both plates of the mold.

The molds had a wider and deeper central area $2.85 \times 13.60 \times 187 \mathrm{~mm}^{3}$ and $3 \times 7.45 \times 187 \mathrm{~mm}^{3}$, respectively, and a longer, narrower and shallower area on each end, to support the metallic core during pressing of the coating, Fig 1a. Stretch foil was applied to prevent sticking of the coating to the mold surface. The coating material was rolled to appropriate thickness and cut to ribbons. First, a ribbon was inserted into the mold, than the metallic electrode core was inserted and cowered with another ribbon. Than the mold was closed with a flat aluminum plate and compressed with a simple 6 t hydraulic press, Fig. 1b. The final product is depicted in the Fig. 1c.
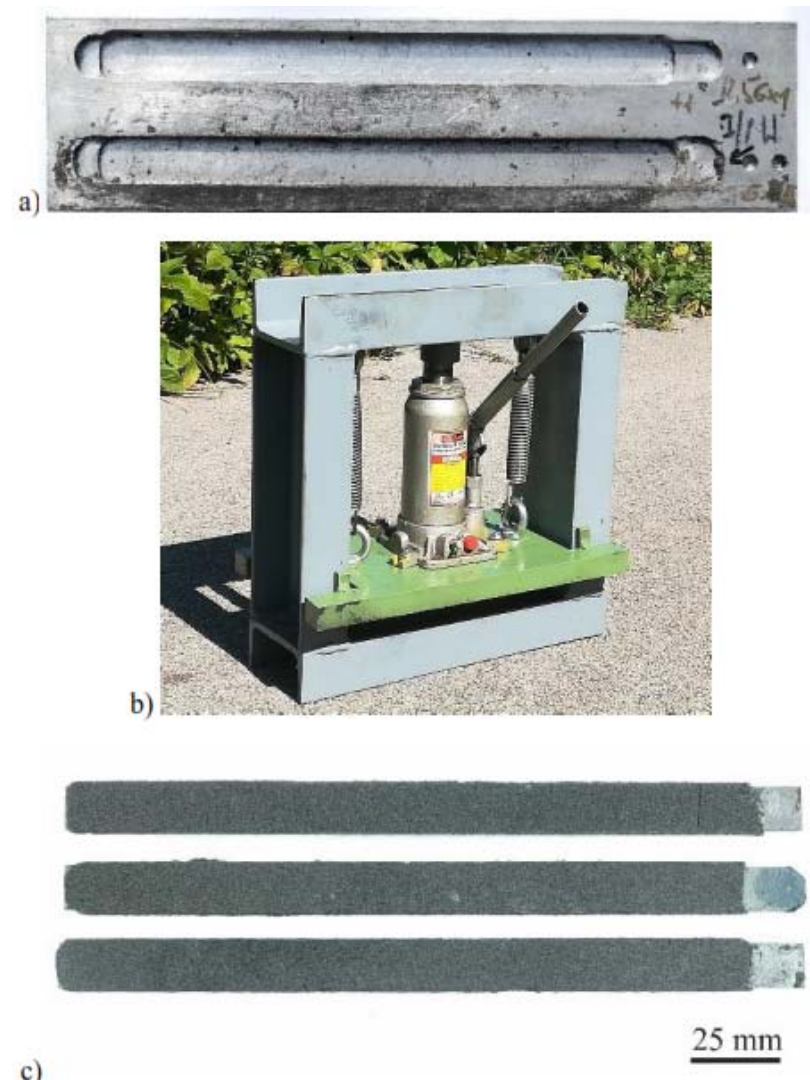

Fig. 1 a) Aluminum model for casting of rectangular coatings; $b$ ) Hydraulic press for coating compression; c) Coated electrode of rectangular core cross-section $12.56 \times 1 \mathrm{~mm}^{2}$

\subsection{Experimental welding and welding properties}

As base material, hot rolled flat steel $80 \times 10 \mathrm{~mm}^{2}$ was used, machined from steel S355JR, according to the standard EN 10025:2004. The bar was cut to $250 \mathrm{~mm}$ long pieces and shot blasted. For experimental welding, the welding source Varstroj Varus 600 was used. Welding current was DC 80-180 A with the electrode holder connected to the negative-pole, Table 3. The angle between the electrode and the base plate was held between $70^{\circ}$ and $80^{\circ}$. 
Table 3: Welding parameters

\begin{tabular}{|c|c|c|c|}
\hline Electrode & Current/A & Sample & Polarity \\
\hline \multirow{4}{*}{$\begin{array}{l}\text { Series } H \text { : } \\
12.56 \times 1 \\
m m^{2}\end{array}$} & 80 & H1 & DCEN \\
\hline & 100 & $\mathrm{H} 2$ & DCEN \\
\hline & 120 & $\mathrm{H} 3$ & DCEN \\
\hline & 140 & $\mathrm{H} 4$ & DCEN \\
\hline \multirow{3}{*}{$\begin{array}{l}\text { Series } K \text { : } \\
6.28 \times 2 \mathrm{~mm}^{2}\end{array}$} & 120 & $\mathrm{H} 3$ & DCEN \\
\hline & 140 & $\mathrm{H} 4$ & DCEN \\
\hline & 160 & $\mathrm{H} 5$ & DCEN \\
\hline \multirow{4}{*}{$\begin{array}{l}\text { Series M: } \\
\phi 4 \mathrm{~mm}\end{array}$} & 120 & M3 & DCEN \\
\hline & 140 & M4 & DCEN \\
\hline & 160 & M5 & DCEN \\
\hline & 180 & M6 & DCEN \\
\hline
\end{tabular}

\subsection{Examination of test welds}

Visual testing was done after welding and cross-sections were machined. Classic metallographic preparation was applied, consisting of grinding, polishing and etching. Macro- and microstructures were examined with optical microscope Leica Wild M10 and Nikon Epiphot 300, respectively. Geometry of the welds was determined: height and area of the weld caps, fusion zone and HAZ. Hardness HV10 across the welds was measured by using a Zwick 3202 apparatus.

\section{RESULTS AND DISCUSSION}

\subsection{Visual examination and weld properties}

With all electrodes, no excessive spattering was observed, and the spatters could be easily removed. The slag spalled by itself and on the weld caps no significant surface defects were found, Fig 2. In general, a flatter weld cap favours easy slag removing. Both rectangular electrodes burned evenly. The arc was narrower than the core and was steadily commuting between the edges.

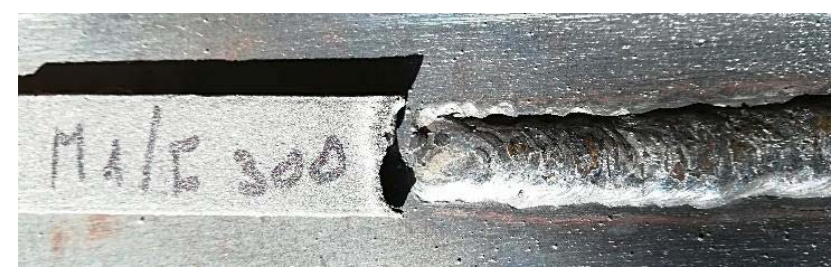

Fig. 2 The rectangular electrode after welding and the weld. The electrode burned evenly. The slag was easy to remove, little spatter.

\subsection{Macro-and microstructure}

On the cross-sections, the most obvious differences were observed between the samples $\mathrm{H}$ and $\mathrm{M}$. Representative macrostructures are shown in Fig. 3. Much higher ratio weld cap width / depth of diffusion zone can be achieved with the rectangular electrode $12.56 \times 1 \mathrm{~mm}^{2}$. However, this is not the only positive effect. Wider welds increase productivity, shallower diffusion zone reduces dilution of the filler material with base material and unique arc travels from one side to another and back, allows more flexibility - uneven surfaces can be easier weld cladded than with standard round type electrode. Less dilution is also favourable for cladding because it means less influence of the base material on the chemical composition of the surface layer and, consequently, the required chemical composition of the surface layer can be achieved with less passes.
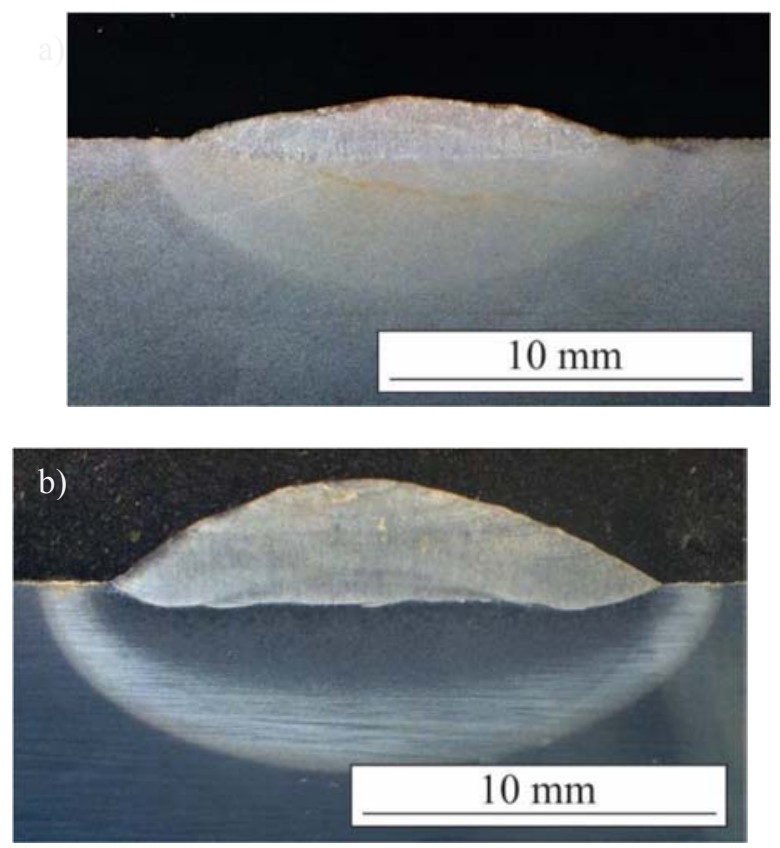

Fig. 3 a) Rectangular electrode $12.56 \times 1 \mathrm{~mm} 2$, sample $\mathrm{H} 4$, welding current $140 \mathrm{~A}$; b) standard cylindrical electrode $4 \mathrm{~mm}$, sample $\mathrm{M6}$, welding current $180 \mathrm{~A}$.

The microstructures in characteristic areas were typical for weldable unalloyed low-carbon construction steels, Fig. 4. Fig a shows the outer area of the HAZ. In the bottom right corner of the micrograph, large ferritic grains can be observed, in size and shape very similar to those in the normalised base material. In this area, the temperature only slightly exceeded Acs temperature while in the upper left corner it already exceeded Ac3 temperature, but only for a short time period, which resulted in very finegrained normalised structure.

Fig. $4 \mathrm{~b}$ shows the coarse-grained area of HAZ. Here, the temperature was higher and material remained austenitic for longer time-period. Quite rapid cooling followed, which lead to growth of large acicular (needlelike) ferritic crystals. Some bainite can also be observed, but bainitefraction is low. Microstructure is predominantly ferritic pearlitic.

Transition area from the HAZ to the fusion zone can be observed in the Fig. 4c. In the lower part of the micrograph, the microstructure consists of equiaxed grains, while in the upper area, longish ferritic grains can be observed, which indicates the transition to columnar solidification. Here, as well as in the rest of the weld, the microstructure is predominantly ferritic - pearlitic with some small bainitic areas. 

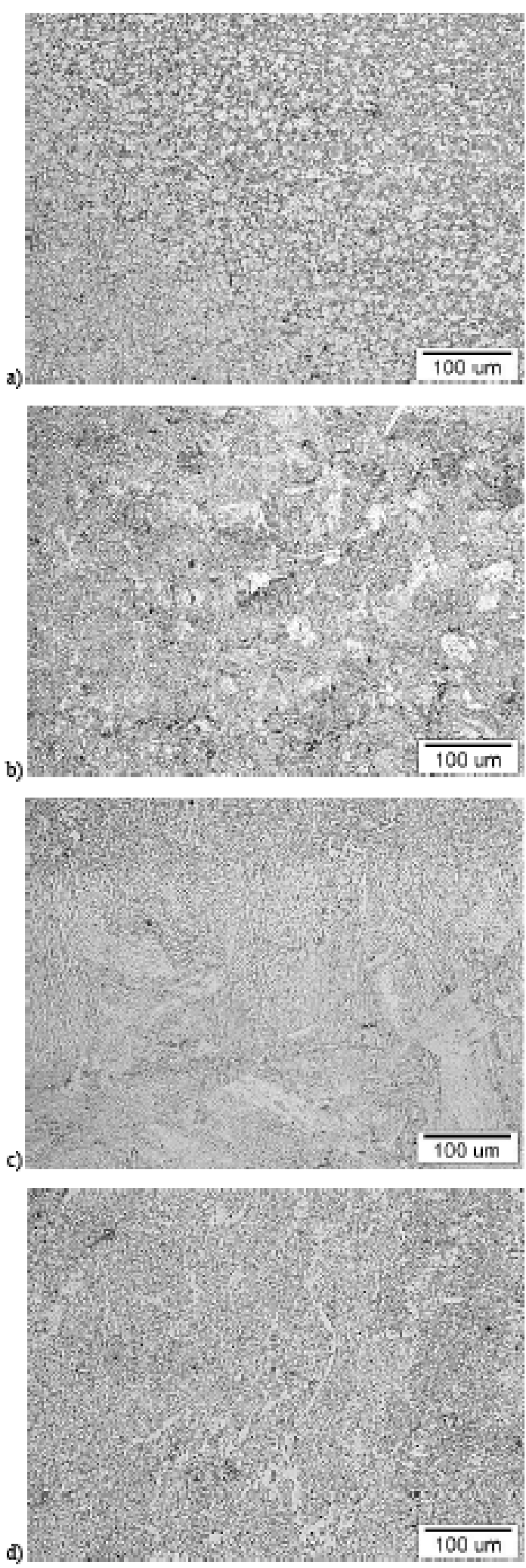

Fig. 4 Characteristic microstructure of the welds and HAZs; a) HAZ, transition zone to unaffected base material; b) HAZ, coarse-grained area; c) Transition from HAZ to fusion zone; d) Fusion zone - area of columnar growth.

Fig. 4d shows columnar structure, characteristic for welds, which forms upon directional solidification. Columnar grains grew upwards. Columnar form was during further cooling adopted by austenite, and below AR3 temperature growth of ferrite started on grain boundaries. Therefore, also the first ferritic grains are pointed upwards. The needle-like side-branches indicate quite high cooling rates. Upon further cooling, the areas in-between transformed into finer structure, whereat the growth of ferrite was still acicular.

\subsection{Dimensions of welds and dilution}

Dimensions of the welds and HAZs were measured and dilution $X$ was calculated according to equation:

$$
X=\frac{A(\text { Fusion zone }(B M))}{A(w l d)} \cdot 100 \%
$$

The geometry is defined as shown in the Fig. 5. Again, the results for series $\mathrm{H}$ and $\mathrm{M}$ were significantly different, while the results for series $\mathrm{K}$ were quite similar to results for series $\mathrm{M}$. Therefore, further discussion will be limited to series $\mathrm{H}\left(12.5 \times 1 \mathrm{~mm}^{2}\right)$ and $\mathrm{M}(\phi 4 \mathrm{~mm})$.

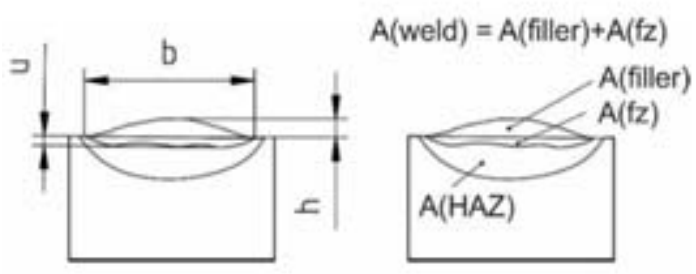

Fig. 5: Characteristic dimensions of the cladded weld; $b$ - Weld cap width, $u$ - Depth of fusion zone, $h$ - Height of the weld cap, A(filler) Area of the weld cap cross-section, $A(f z)$ - Area of the fusion zone cross-section, $A(H A Z)$ - Area of the HAZ cross-section.

While the current with cylindrical electrode had to be at least in the vicinity of the range, recommended by the manufacturer, i.e. 130-170 A, to obtain a good quality deposition layer, the current could be as low as $80 \mathrm{~A}$ with the rectangular electrode $12.56 \times 1 \mathrm{~mm}^{2}$.

The dimensions of the welds are presented in the Fig. 6 . Cross-section areas of weld cups, fusion zones and HAZs and dilutions vs. welding current are shown in the Fig. 7.

The diagrams in fig. 6 show that for the rectangular electrode, a current about 80-100 A was optimum with respect to weld width and fusion zone depth. Similar weld widths could be obtained with cylindrical electrode with significant higher currents, about 120-140 A. However, with the cylindrical electrode, at comparable weld widths the fusion zone was deeper, Fig. 6a, and its area larger, Fig. $7 \mathrm{~b}$.

Due to possibility to weld with currents as low as $80-100$ A, shallower and smaller HAZs and less dilution could be achieved with the rectangular electrode than with standard cylindrical electrode, Figs. 7c and 7d. 
a)

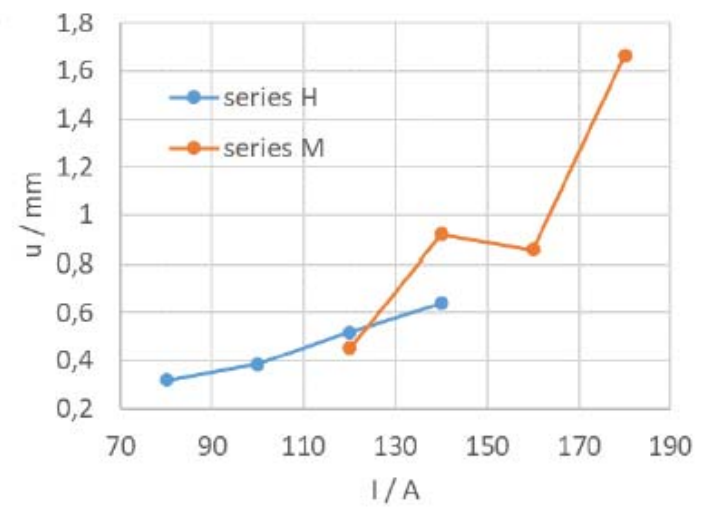

b)

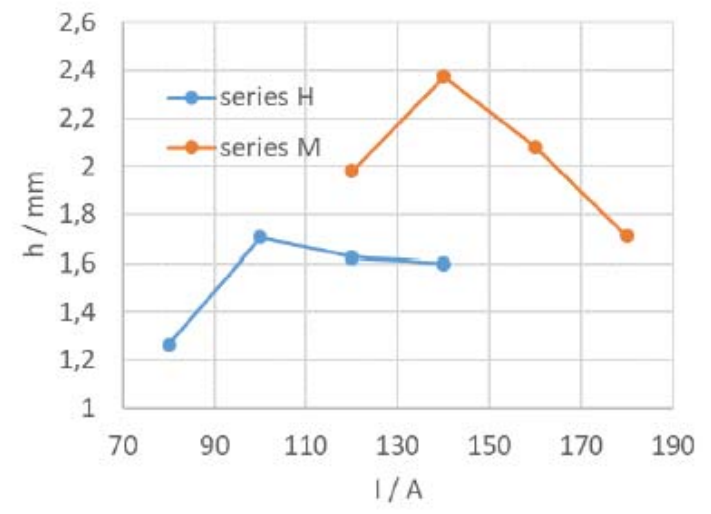

c)

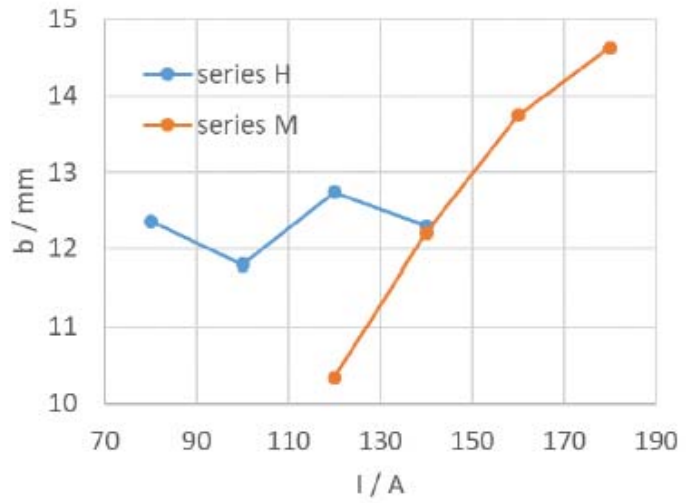

Fig. 6: Dimensions of the welds: a) Depth of fusion zones vs. welding current; b) Height of the weld cap vs. welding current; c) Weld cap width vs. welding current.

\subsection{Hardness}

Vickers hardness HV10 was measured horizontal and vertical across the weld area. Positions and directions of measuring are shown in the Fig. 8.

As samples H3 and M3 and samples H4 and M4 were welded with comparable currents, only the hardness of this two pairs can be compared. The hardness of samples $\mathrm{H} 3$ and H4 is presented in Fig. 9 and Fig. 10, respectively. In all samples $H$ the hardness across the weld was very uniformed, Fig 9. Most uniformed was hardness across the weld in all cases in horizontal direction, where only negligible differences could be noticed, Figs. 9a and 9c. a)

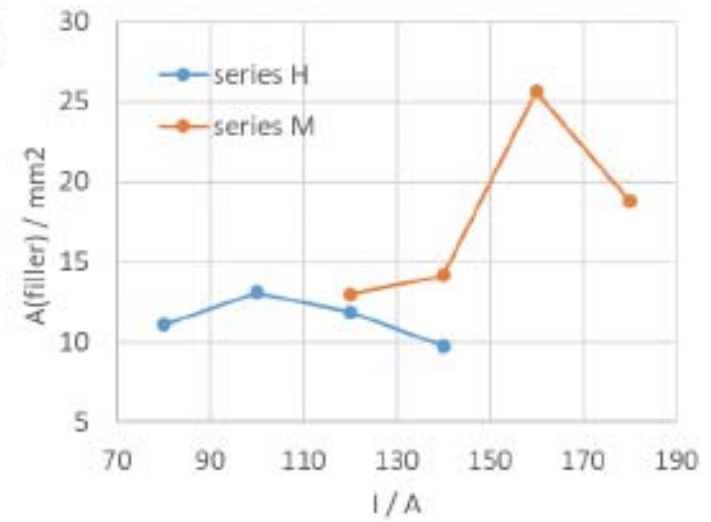

b)

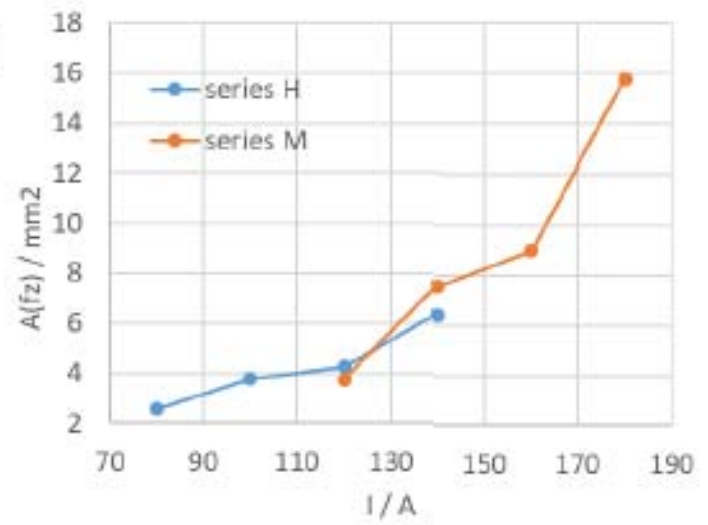

c)

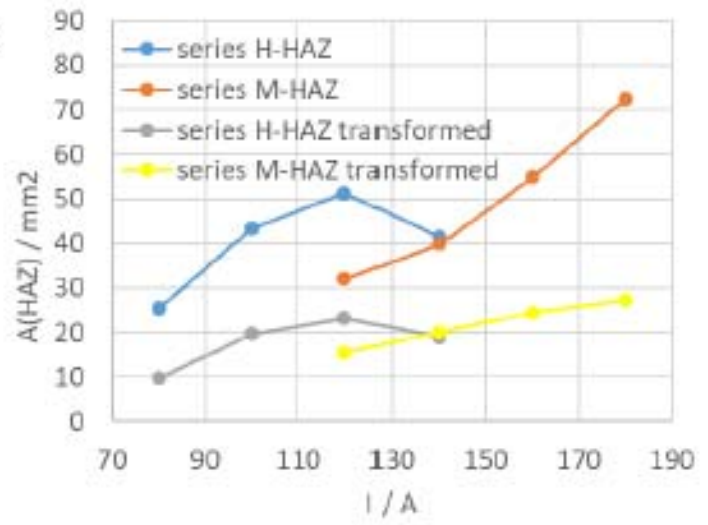

d)

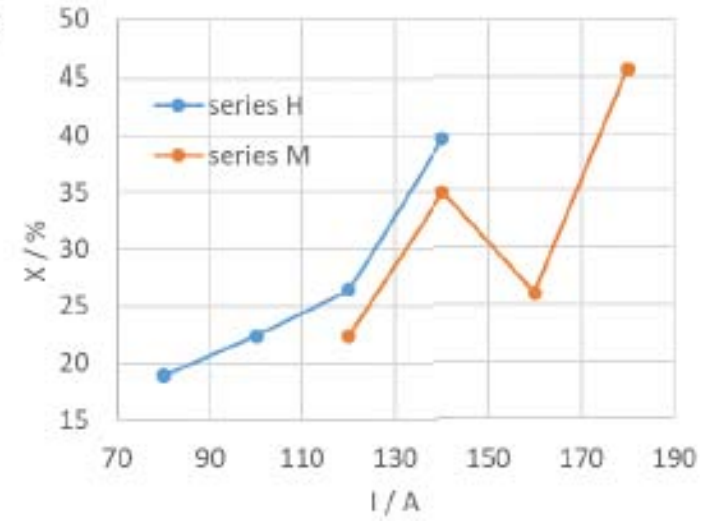

Fig. 7 a) Cross-section area of weld cap; b) Cross-section area of fusion zone; c) Total cross-section area of HAZ (upper curves) and cross-section area of phase-transformed HAZ (lower curves); d) dilution $X$. 


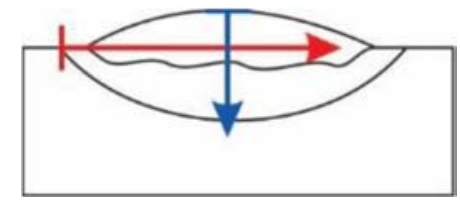

Fig. 8 Positions and directions of hardness measurements.
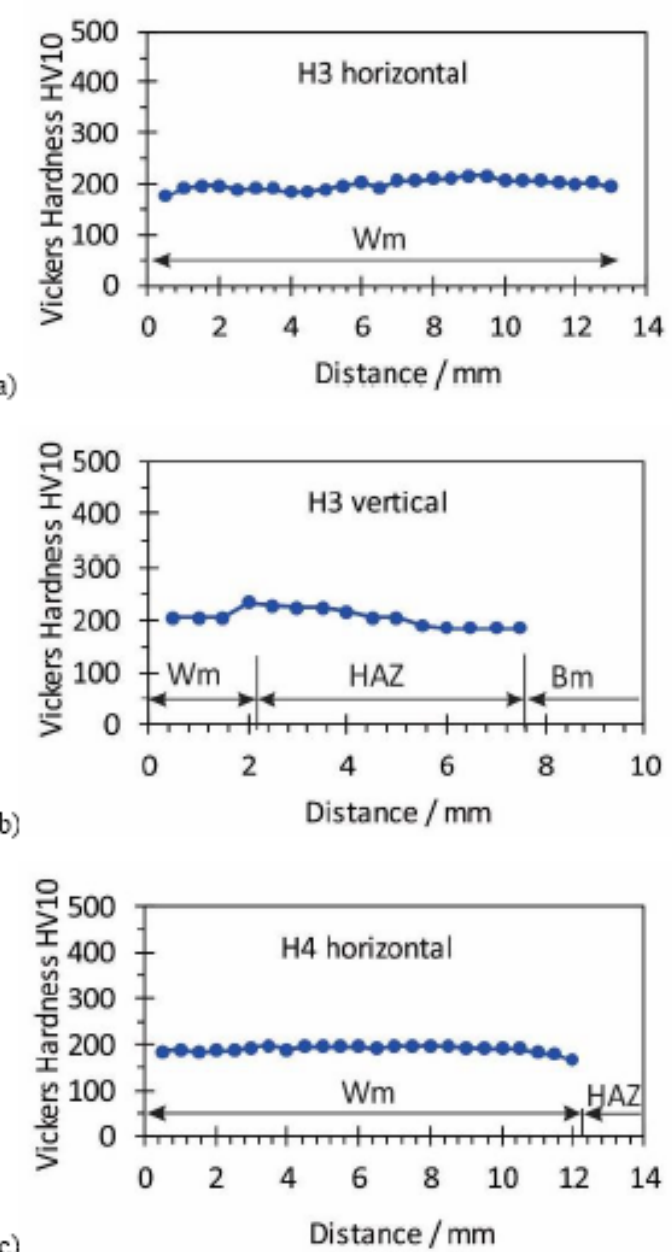

c)

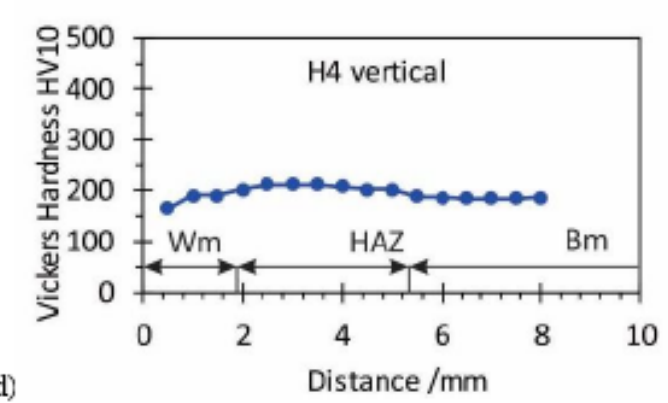

Fig. 9 a) Hardness of samples $\mathrm{H}$ - rectangular electrode $12.56 \times 1 \mathrm{~mm} 2$; a) Sample H3, 120 A, horizontal direction; b) Sample $H 3$, vertical direction; c) Sample H4 140 A, horizontal direction; $d$ ) Sample H4, vertical direction. Abbreviations represent Wm - Weld metal, $H A Z$ - Heat affected zone, Bm - Base material.

The least uniform was the hardness of the sample $\mathrm{H} 3$ measured in vertical direction, where it increased from approx. 200 HV10 to approx. 240 HV10 at the transition from weld metal to HAZ. It should be noted that this was the highest hardness of all samples from series $\mathrm{H}$.

Also the hardness of samples M3 and M4 measured in horizontal direction was very uniformed, Figs. 10a and 10c. This can be explained with the fact that practically all measurements in horizontal direction were done in the weld metal.
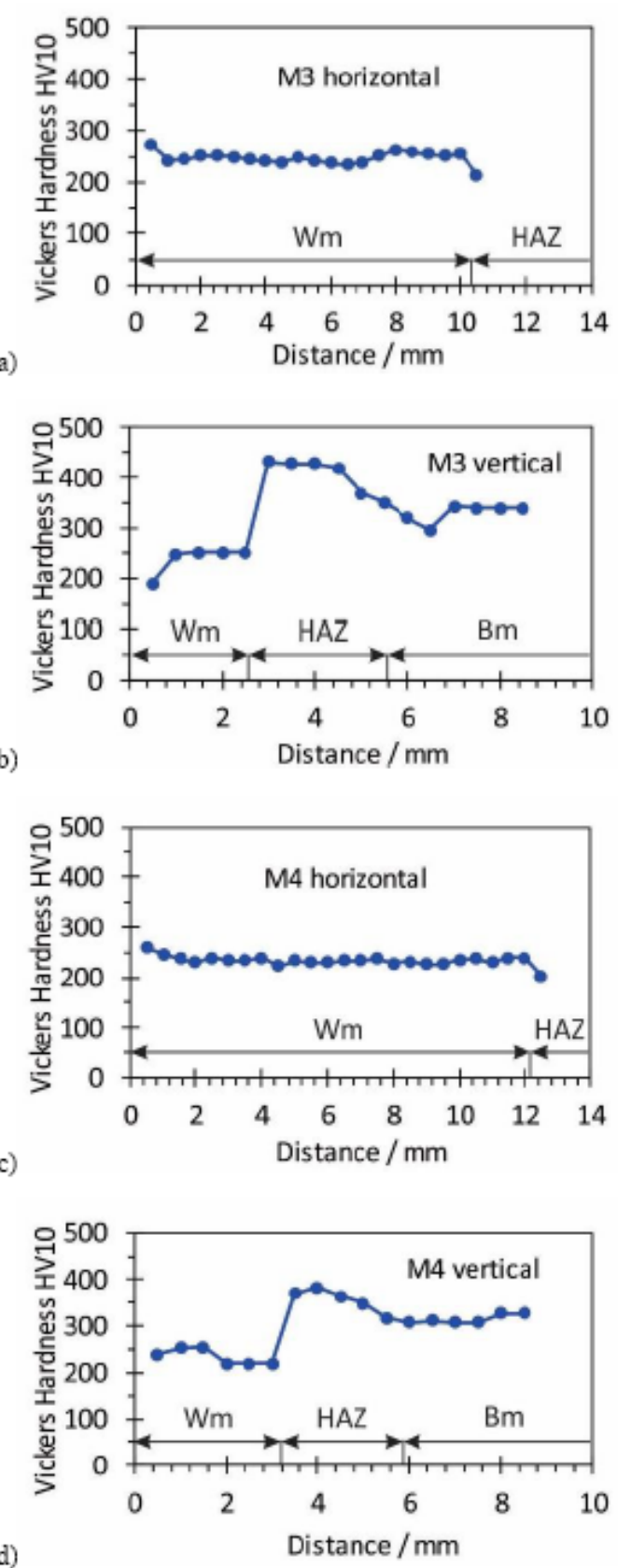

Fig. 10 Hardness of samples $M$ - standard cylindrical electrode $\phi 4$ $\mathrm{mm}$; a) Sample M3, 120 A, horizontal direction; b) Sample M3, vertical direction; c) Sample M4, 180 A, horizontal direction; d) Sample M4, vertical direction. Abbreviations represent Wm - Weld metal, HAZ Heat affected zone, $\mathrm{Bm}$ - Base material.

Much less uniformed was the hardness of samples $\mathrm{M}$ in the vertical direction, even less than in samples $H$. The hardness of HAZ in samples $M$ was between approx.250 HV 10 and approx. 430 HV10. The least uniformed was 
the hardness in vertical direction in sample M3, where it increased from $250 \mathrm{HV} 10$ to $433 \mathrm{HV} 10$ in transition area from weld metal to HAZ. 344 HV10 was also the highest hardness measured in all samples included in this investigation.

\section{CONCLUSIONS}

Coated electrodes of rectangular cross-sections of $6.28 \times 2$ $\mathrm{mm}^{2}$ were manufactured. The chemical compositions of the metallic core and the coating corresponded to the standard cylindrical electrode Rutilen 2000 S. Weld cladding was carried out with rectangular electrodes as well as with standard electrodes Rutilen $2000 \mathrm{~S}$ of the equal core cross-section area. The results lead to following conclusions:

- No excessive spattering was observed, and the spatters could be easily removed. The slag spalled by itself immediately after welding.

- The rectangular electrodes burned evenly.

- The arc was narrower than the core and was steadily commuting between the both edges.

- The results with the rectangular electrodes $6.28 \times 2.0$ $\mathrm{mm}^{2}$ (series M) were very similar to results with the cylindrical electrodes.

- With the rectangular electrodes $12.56 \times 1 \mathrm{~mm}^{2}$, significantly lower welding current was sufficient to obtain a good quality of the deposition layer than with the standard cylindrical electrode.

- For the $12.56 \times 1 \mathrm{~mm}^{2}$ rectangular electrode, a current of about 100-120 A was optimum with respect to weld width and fusion zone depth.

- At comparable weld widths, the fusion zone was deeper and its area larger with the cylindrical electrode.

- Due to possibility to weld with currents as low as $80100 \mathrm{~A}$, shallower and smaller HAZs and less dilution can be achieved with the rectangular $12.56 \times 1 \mathrm{~mm}^{2}$ electrode than with standard cylindrical $\phi 4 \mathrm{~mm}$ electrode.

- Increase of hardness in the transition zone from weld metal to HAZ was much higher with standard cylindrical electrode than with rectangular electrode $12.56 \times 1 \mathrm{~mm}^{2}$.

\section{References}

[1.] Yan M. (1998). An experimental study of the remelting of an Fe-C-Cr-B overlay with a microbeam plasma arc. Surf. Coat. Technol. 99, pp.132-139.

[2.] Karimi A., Verdon Ch. (1993). Hydroabrasive wearbehaviour of high velocity oxyfuel thermally sprayed WC-M coatings. Surf. Coat. Technol. 62, pp.493-498.

[3.] Jha A.K., Prasad B.K., Dasgupta R., Modi O.P. (1999). Influence of material characteristics on the abrasive wear response of some hardfacing alloys. Mater. Eng. Perf. 8, pp. 190-196

[4.] Zhu B.D., Zeng X.Y, Z.Y. Tao Z.Y., Yang S.G., Cui K. (1993) . Coarse cemented WC particle ceramic-metal composite coatings produced by laser cladding. Wear. 170, pp.161-166.

[5.] Xie S., Li W., Pan Z., Chang B., Sun L. (2000) Carbon nanotube arrays. Mater. Sci. Eng. A 286 pp.11-15.

[6.] Wolfe D.E., Singh J., Krishnan N. (2002) . Synthesis of titanium carbide/chromium carbide multilayers by the covaporation of multiple ingots by electron beam physical vapor deposition. Surf. Coat. Technol. 160, pp.206-218.

[7.] Crespo A. C., Scotti A., Pérez, M. R. (2008). Operational behavior assesment of coated tubular electrodes for SMAW hardfacing. Journal of Materials Processing Technology, 199 (1-3), pp. 265-273.

[8.] Brezinová J., Draganovská D., Guzanová A., Balog P., Viňáš J. (2016). Influence of the Hardfacing Welds Structure on Their Wear Resistance. Metals, 6, pp.2 1-12, doi: 10.3390

[9.] Buchely M. F., Gutierrez J. C., León L.M., Toro A. (2005). The effect of microstructure on abrasive wear of hardfacing alloys. Wear, 259 (1-6), pp. 5261.

[10.] Bjelajac E., Lojen G., Vuherer T. (2017). Izdelava ploščate oplaščene electrode in testno navarjanje na konstrukcijsko pločevino. In (eds.) A. Lešnjak, J. Tušek, T.Vuherer, S. Zorko: Zbornik dneva varilne tehnike, Celjski sejem d.d., pp. 96-101.

[11.] Bjelajac E., Vuherer T., Skumavc A., Lojen G. (2017). Weld cladding with coated electrode od fectangular cross-section. In (eds) I. Samardžić, B. Despotović, Proceedings of 9. international sceintificproffessional conference SBW 2017, Slavonski Brod pp. 32-41. 